\title{
Competências digitais no campo de públicas: a formação de gestores públicos do século XXI
}

Digital skills in the public field: the formation of 21st century public managers

\author{
Letícia Dufloth Bianchini ${ }^{1}$ \\ Marco Antônio Almeida Silva ${ }^{2}$ \\ Max Melquíades Silva ${ }^{3}$ \\ Simone Cristina Dufloth ${ }^{4}$
}

\section{RESUMO}

O presente artigo analisa as competências digitais no contexto da formação e da atuação de gestores públicos, que, em virtude das inovações características do século $\mathrm{XXI}$, se configuram, cada vez mais, como elementos essenciais para a excelência do setor público. De maneira específica, são estudados: o percentual de carga horária dedicado a conteúdos direta e indiretamente relacionados à temática da tecnologia de informação e a visão de estudantes e especialistas sobre o conteúdo ministrado; as percepções de estudantes do campo de públicas sobre seu domínio e experiência no que concerne ao uso das Tecnologias de Informação e Comunicação (TIC); e a importância das tecnologias no setor público a partir das perspectivas de alunos e especialistas no campo de públicas. A metodologia se caracteriza como exploratória de abordagem qualitativa e quantitativa, realizada a partir de pesquisa bibliográfica, documental e de campo. Foram aplicados questionários e realizadas entrevistas com estudantes e especialistas da área, e desenvolvida análise das matrizes curriculares dos cursos do campo de públicas das dez instituições mais bem avaliadas segundo o Conceito Enade 2015. Os resultados encontrados trazem indícios de desafios na atuação de gestores públicos, em virtude de dificuldades relacionadas ao uso de ferramentas tecnológicas no exercício de suas atividades. Além disso, constata-se um ainda incipiente desenvolvimento de competências digitais na formação de gestores públicos.

Palavras-chave: Competências Digitais no Campo de Públicas; TIC no Setor Público; Formação de Gestores Públicos; Atuação de Gestores Públicos.

\begin{abstract}
This article analyzes digital competences in the context of the training and performance of public managers, which, due to the characteristic innovations of the 21 st century, are increasingly becoming essential elements for the excellence of the public sector. Specifically, it is studied: the percentage of hours dedicated to content directly and indirectly related to the topic of information technology and the view of students and experts on the content taught; the perceptions of students in the Public Administration area about their mastery and experience regarding the use of Information and Communication Technologies (ICT); and the importance of technologies in the public sector from the perspectives of students and experts in the Public Administration area.
\end{abstract}

\footnotetext{
${ }^{1}$ Graduanda em Administração Pública pela Escola de Governo Professor Paulo Neves de Carvalho da Fundação João Pinheiro. Email: letdufloth@gmail.com.

${ }^{2}$ Graduando em Administração Pública pela Escola de Governo Professor Paulo Neves de Carvalho da Fundação João Pinheiro. Email: marcoalmeidas@hotmail.com.

${ }^{3}$ Doutorando em Ciência da Informação pela Universidade Federal de Minas Gerais. Pesquisador em Ciência e Tecnologia na Escola de Governo Professor Paulo Neves de Carvalho da Fundação João Pinheiro. E-mail: max.silva@fjp.mg.gov.br.

${ }^{4}$ Doutora em Ciência da Informação pela Universidade Federal de Minas Gerais. Pesquisadora em Ciência e Tecnologia na Escola de Governo Professor Paulo Neves de Carvalho da Fundação João Pinheiro. E-mail: simone.dufloth@fjp.mg.gov.br.
} 
The methodology is characterized as exploratory of a qualitative and quantitative approach, based on bibliographical, documentary and field research. Questionnaires were applied and interviews were conducted with students and specialists in the field, and the curricular matrices of the courses in the Public Administration area of the ten most evaluated institutions according to the Enade 2015 Concept were analyzed. The results found show signs of challenges in the performance of public managers, due to difficulties related to the use of technological tools in the exercise of their activities. In addition, there is still an incipient development of digital skills in the training of public managers.

Keywords: Digital Skills in Courses in the Public Administration Area; ICT in the Public Sector; Training of Public Managers; Performance of Public Managers.

\section{Introdução}

A era digital provoca impactos em todas as esferas de governo e impulsiona mudanças inovadoras e criativas na administração pública e na prestação de serviços públicos. Nesse sentido, os gestores públicos devem estar preparados para esse cenário por meio de competências digitais. Tais competências revelam a capacidade das pessoas em utilizar com segurança e autonomia as Tecnologias de Informação e Comunicação (TIC), o que envolve habilidades para lidar com ferramentas tecnológicas. Sendo assim, essas competências se configuram como essenciais ao desempenho de funções públicas, especialmente dentro do contexto de atuação dos gestores do século XXI, ainda que no Brasil, segundo Silva e Behar (2019), o debate sobre competências digitais seja incipiente, o que reforça a importância de estudos nessa área.

De acordo com Rada, Vidal e Cervera (2011), as competências digitais se situam no âmbito da sociedade do conhecimento e são refletidas na capacidade decisória e na solução de problemas em qualquer ambiente de aprendizagem, seja ele pessoal, profissional ou social. Essa premissa está associada ao quadro proposto por Carretero, Vuorikari e Punie (2017), no âmbito da Comissão Europeia, por meio do Digital Competence Framework for Citizens (DigComp 2.1). O quadro identifica e classifica as competências digitais em diferentes áreas e níveis, de forma a categorizar os graus de perícia dos indivíduos em relação ao emprego do meio digital em seus afazeres, tais como a utilização dos dispositivos digitais em si, ou o savoir-faire do sujeito acerca de seus desafios e de sua autonomia na conclusão de tarefas.

Esse estudo orientou a elaboração do presente artigo no sentido de identificar o desenvolvimento de competências digitais tanto na formação quanto na atuação de gestores públicos. Essas competências são fundamentais para a melhoria da qualidade do setor público, uma vez que suscitam transformações criativas e inovadoras que contribuem para a eficiência e a rapidez de processos, para a transparência governamental e para o estabelecimento de canais de aproximação do governo em relação aos cidadãos para a prestação dos serviços públicos e para a participação cidadã. A literacia digital no setor público pode expandir iniciativas fundamentais no contexto da era digital, como a ampliação e o aprimoramento da governança digital, que impulsiona a melhoria da qualidade dos serviços públicos e estimula a participação social e democrática por meio do ambiente digital.

Sendo assim, nota-se a primordialidade de incitar o desenvolvimento das competências digitais no âmbito estatal, com o intuito de dinamizar as atividades exercidas na esfera pública. Dessa forma, disciplinas voltadas para temáticas que estimulem tais competências em cursos de formação na área de Administração Pública criam oportunidades para os gestores públicos na assimilação desses contextos emergentes. Uma vez que as tecnologias digitais avançam vertiginosamente, a formação dos profissionais que se inserem nesse contexto deve configurar-se de forma dinâmica a fim de suprir necessidades profissionais que englobam tanto fundamentos teóricos essenciais, além de conteúdos emergentes voltados ao desenvolvimento de competências digitais no âmbito dos profissionais do futuro. 
Dentro dessa seara, esta pesquisa se justifica ao estudar o tratamento conferido à formação e à atuação de gestores públicos no que se refere às competências digitais. Tendo em vista o exposto, o presente artigo tem como objetivo analisar as competências digitais no âmbito da formação e da atuação de gestores públicos. Especificamente, pretende-se: a) identificar, em cursos do campo de públicas, o percentual de carga horária dedicado a conteúdos direta e indiretamente relacionados à temática da tecnologia de informação e a visão de estudantes e especialistas sobre o conteúdo ministrado; b) investigar a percepção de estudantes sobre seu domínio no que concerne ao uso das TIC; c) identificar a importância das TIC no setor público a partir da perspectiva de estudantes e especialistas no campo de públicas.

Para tanto, o presente trabalho está organizado da seguinte maneira: primeiramente, descreve-se a metodologia utilizada para a análise realizada, que contou com pesquisa bibliográfica, documental e de campo. Logo após, de modo a trazer uma maior clareza quanto aos conceitos que sustentam a pesquisa, é feito um referencial teórico a partir de uma análise bibliográfica. Posteriormente, são apresentados os resultados da pesquisa desenvolvida, em atendimento aos objetivos relatados.

\section{Metodologia}

A metodologia utilizada classifica-se como exploratória de abordagem qualitativa e quantitativa. O caráter exploratório da pesquisa se caracteriza por proporcionar uma visão geral acerca de determinado assunto e esse tipo de pesquisa tem a finalidade de desenvolver conceitos e ideias para estudos posteriores (GIL, 2008).

A coleta de dados envolveu pesquisa bibliográfica, documental e de campo. A pesquisa bibliográfica foi realizada a partir de literatura sobre Administração Pública, Tecnologias de Informação e Comunicação no setor público, governo eletrônico e formação de gestores públicos. Utilizou-se, pois, de artigos científicos, em especial os fundamentos do DigComp 2.1 (CARRETERO; VUORIKARI e PUNIE, 2017).

O levantamento documental se deu a partir das matrizes curriculares e dos projetos pedagógicos dos cursos de bacharelado do campo de públicas das dez instituições mais bem avaliadas segundo o Conceito Enade 2015. Dentre os diversos parâmetros existentes, utilizou-se esse indicador, haja vista que ele analisa o desempenho de estudantes em uma prova que avalia os conteúdos de formação dos futuros gestores púbicos. O critério de seleção para a amostragem analisada se justifica dada a ampla gama de cursos do campo de públicas em nível de bacharel existentes no Brasil, buscando-se representar cursos reconhecidos como de maior excelência.

A partir das instituições e cursos identificados dentro desses critérios, foi feita uma análise curricular dos referidos cursos com o intuito de verificar a atenção dada a disciplinas voltadas para a abordagem do uso de Tecnologias da Informação e Comunicação, a partir de indícios que demonstram conteúdos relacionados à $\mathrm{TI}$ na formação dos gestores. Além disso, a pesquisa documental também envolveu consulta a sites governamentais concernentes ao Conceito Enade.

A análise das matrizes curriculares e projetos pedagógicos, realizada de maneira quantitativa, considerou a carga horária de disciplinas relacionadas à TI diretamente, em que o objetivo do conteúdo da disciplina é aprender temáticas relacionadas a TIC e isso está explícito nas ementas das disciplinas; e indiretamente, quando o objetivo da disciplina não é o aprendizado sobre tecnologias, mas recursos tecnológicos são usados como meio para atingi-lo. Pode-se exemplificar como as disciplinas que abordam TI de maneira direta as de Informática, Sistemas de Informação, Governo Eletrônico, dentre outras; e as que tratam do tema de forma indireta as de Estatística, Métodos Quantitativos, Gestão de Processos, etc.

A pesquisa de campo, por sua vez, envolveu a realização de questionário semiaberto a alunos de alguns dos referidos cursos que são objeto deste trabalho. O questionário foi divulgado para grupos de Whatsapp de estudantes das instituições analisadas de maneira aberta, e a coleta de dados se deu por meio do Google 
Forms. O questionário ficou disponível para resposta durante o período de uma semana, na terceira semana de junho de 2019. Nesse período, foram coletadas dezesseis respostas que contribuíram para o presente estudo.

A análise desses questionários ocorreu de forma quantitativa no que diz respeito às questões fechadas com relação à autoavaliação dos respondentes acerca de seu domínio sobre o uso das TIC; e qualitativa nos demais aspectos abordados, como a percepção dos estudantes sobre conteúdos sobre $\mathrm{TI}$ ao longo do curso e sobre o desempenho de gestores públicos, a partir de experiências profissionais dos alunos.

Além disso, foram realizadas entrevistas com três professores doutores especialistas na área de Administração Pública. Nessas entrevistas, as questões envolveram a percepção dos respondentes sobre as TIC nas áreas de formação e de atuação de gestores públicos, bem como sua visão acerca da importância e dos desafios sobre o tema para a Administração Pública e tendências futuras. A partir das informações e dos dados coletados, foi possível estabelecer correlações entre as matrizes curriculares as percepções dos especialistas e dos alunos, com vistas ao atingimento dos objetivos estabelecidos para este trabalho.

\section{Competências Digitais e a Formação de Gestores Públicos: Principais Fundamentos Teóricos}

\subsection{Competências e literacia digital: novos desafios para o século XXI}

O ritmo da inovação tecnológica está constantemente evoluindo. A expansão e a difusão das Tecnologias de Informação e Comunicação têm contribuído para a proliferação de conteúdos multimidiáticos e para a necessidade do uso consciente e responsável da informação dentro do mundo globalizado. Nesse contexto, o comportamento da sociedade se modifica e sofre influência do conteúdo informacional que recebe, utiliza e dissemina. Para saber lidar com esse ambiente digital é importante que os indivíduos detenham competências que Ihes permitam aproveitar de maneira plena o potencial tecnológico disponível, além de serem capazes de discernir sobre o uso de ferramentas, dados e informações dentro de seus propósitos e necessidades. Dessa forma, se por um lado a difusão da Internet possui especial papel para uma inclusão plena dos indivíduos na Sociedade da Informação, a ausência dessas novas competências digitais se traduz em exclusão. (VAN DAURSEN, 2010)

Nesse cenário, destaca-se o termo literacia digital, que representa a habilidade de identificar, compreender, interpretar, criar, comunicar e computar, utilizando materiais impressos e escritos associados a contextos variados. Portanto, a literacia envolve um processo de aprendizagem contínua, que permite aos indivíduos alcançarem os seus objetivos, desenvolver o seu conhecimento e potencial, além de poderem participar plenamente na sociedade (MOELLER et. al., 2011).

No contexto global e com o desenvolvimento das TIC, é importante que as comunidades digitais ofereçam oportunidades no que diz respeito à educação, aprendizagem, interação, participação, envolvimento cívico e auto expressão (JENKINS et al., 2009 apud SEBASTIÃO, 2014). Nesse alinhamento, a literacia digital engloba a capacidade interagir com outros atores por meio da Internet, o que leva à necessidade de compreendê-la e utilizá-la de forma crítica, ética, segura, eficiente, eficaz e responsável. Sendo assim, é um processo de aprendizagem aplicado ao mundo digital, a partir do uso de ferramentas digitais para identificar, acessar, gerenciar, integrar, avaliar, analisar e sintetizar recursos digitais, construir novos conhecimentos nesse meio, criar expressões midiáticas e se comunicar com outros, a fim de possibilitar uma ação social construtiva e refletir acerca desse processo (MARTIN, 2005).

De acordo com Sebastião (2014), a literacia digital permite dotar o indivíduo de competências e conhecimentos que determinam o seu sucesso profissional e proporcionam meios de participação ativa de 
cidadania. Essas competências se direcionam para melhor lidar com o ambiente digital que configura o contexto da Sociedade da Informação (ALA-MUTKA, 2011; AZEVEDO, PEDRO e SANTOS, 2015). Para Azevedo, Pedro e Santos (2015), as competências digitais podem ser estruturadas em duas dimensões. A primeira dimensão está relacionada aos fatores relativos ao meio; isto é, diz respeito à disponibilidade das TIC e o acesso a elas, como computadores, Internet e smartphones. A segunda, que é a competência individual, inclui: ter aptidões operacionais básicas para utilização dos fatores relativos às TIC; aplicar esses conhecimentos em áreas como a vida profissional, aprendizagem e participação na sociedade; e ter um conjunto de atitudes e de princípios éticos, por exemplo, uso confiante e uso criativo.

Uma referência para o desenvolvimento de competências digitais é o Digital Competence Framework for Citizens, também conhecido como DigComp. Publicado pela primeira vez em 2013, foi atualizado pela última vez em 2017 (DigComp 2.1) com incrementos na terminologia e no modelo conceitual, além de conter na apresentação exemplos da sua implementação em nível europeu, nacional e regional.

A versão DigComp 1.0 apresentava três níveis de proficiência (básico, intermédio e avançado), que foram aumentados para oito níveis na versão atual, o DigComp 2.1. Para cada competência, foram definidos oito níveis de proficiência que se traduzem em resultados de aprendizagem, inspirados na estrutura e vocabulário do Quadro Europeu de Qualificações (QEQ). Além disso, a descrição de cada nível contém conhecimentos, habilidades e atitudes, descritos num único descritor por nível de cada competência; isso equivale a 168 descritores.

Dessa forma, pode-se dizer que o DigComp 2.1. possui como foco a ampliação dos níveis de proficiência, novos exemplos para o uso desses níveis, com o objetivo de apoiar as partes interessadas na implementação do Quadro (CARRETERO, VUORIKARI e PUNIE, 2017).

O DigComp possui cinco áreas de competência, que englobam 21 competências, apresentando, cada uma, oito níveis de proficiência. A primeira área de competência "Literacia de informação e de dados" resume-se em localizar e articular as necessidades de informação e de dados, bem como em julgar a relevância da fonte e seu conteúdo. Entende-se a segunda área "Comunicação e colaboração" como a interação, comunicação e colaboração através de tecnologias digitais, tendo consciência da diversidade cultural e geracional, além da participação na sociedade e garantia da identidade digital. A terceira área "Criação de conteúdo digital" diz respeito à criação e edição de conteúdo digital para melhorar e integrar informações, compreendendo como os direitos autorais e as licenças devem ser aplicados. A quarta área de competência "Segurança" engloba a proteção dos dispositivos, conteúdo, dados pessoais e privacidade em ambientes digitais, bem como da saúde física e psicológica. É importante também estar ciente das tecnologias digitais para o bem-estar social e a inclusão social e do impacto ambiental das tecnologias digitais e seu uso. A quinta área "Resolução de Problemas" pode ser sumarizada em identificar e resolver os problemas em ambientes digitais, fazendo uso de ferramentas para inovar os processos e produtos em consonância à evolução digital (CARRETERO, VUORIKARI e PUNIE, 2017).

O Quadro 1 apresenta os oito níveis de proficiência em relação à competência digital propostos por Carretero, Vuourikari e Punie (2017). 
Quadro 1 -Níveis de proficiência descritos no DigComp 2.1.

\begin{tabular}{|c|c|c|c|}
\hline Nível & Complexidade da tarefa & Autonomia & Domínio cognitivo \\
\hline 1 & Tarefas simples & Com orientação & Lembrar \\
\hline 2 & Tarefas simples & $\begin{array}{l}\text { Com autonomia e orientação } \\
\text { onde necessário }\end{array}$ & Lembrar \\
\hline 3 & $\begin{array}{l}\text { Tarefas bem definidas e } \\
\text { rotineiras; } \quad \text { Problemas } \\
\text { simples }\end{array}$ & Sozinho(a) & Compreender \\
\hline 4 & $\begin{array}{l}\text { Tarefas bem definidas e } \\
\text { não rotineiras; Problemas } \\
\text { simples }\end{array}$ & $\begin{array}{l}\text { De modo independente e de } \\
\text { acordo com as próprias } \\
\text { necessidades }\end{array}$ & Compreender \\
\hline 5 & $\begin{array}{l}\text { Tarefas e problemas } \\
\text { diferentes }\end{array}$ & Orientando outros & Aplicar \\
\hline 6 & Tarefas mais apropriadas & $\begin{array}{l}\text { Adaptando-se a outros em um } \\
\text { contexto complexo }\end{array}$ & Avaliar \\
\hline 7 & $\begin{array}{l}\text { Problemas complexos } \\
\text { com definição limitada }\end{array}$ & $\begin{array}{l}\text { Contribuindo para a prática } \\
\text { profissional; Orientando outros }\end{array}$ & Criar \\
\hline 8 & $\begin{array}{l}\text { Problemas complexos } \\
\text { com muitos fatores que } \\
\text { interagem entre si }\end{array}$ & $\begin{array}{l}\text { Propondo novas ideias e } \\
\text { processos para a área }\end{array}$ & Criar \\
\hline
\end{tabular}

Fonte: Adaptado de Carretero, Vuorikari e Punie (2017).

Conforme demonstrado no Quadro 1, cada nível representa um incremento na aquisição da competência pelos indivíduos, de acordo com o seu desafio cognitivo, a complexidade das tarefas com as quais são capazes de lidar e a sua autonomia para concluí-las. É interessante notar que, à medida que os níveis de proficiência aumentam, também aumenta a capacidade dos indivíduos de realizar transformações no cenário profissional.

Dessa forma, garantir que os indivíduos em uma organização melhorem suas competências digitais significa caminhar na direção de uma transformação do ambiente organizacional, para além do uso da tecnologia para a resolução de problemas pontuais. Aplicada ao setor público, essa concepção está atrelada à possibilidade do aumento da eficiência dos processos, da melhoria na prestação de serviços públicos e na transformação do paradigma de governança.

3.2. Formação de gestores públicos: principais linhas e conteúdos para o desenvolvimento de competências digitais

As estratégias dos governos digitais são essenciais para a institucionalização dos objetivos relativos às políticas públicas, além de alinhar as prioridades governamentais e integrar ações coordenadas em prol da gestão pública eficiente e da prestação de serviços públicos de qualidade. Os benefícios potenciais da transformação de inúmeros serviços públicos presenciais em serviços públicos disponibilizados em meio 
digital incluem a redução de custos e os ganhos de eficiência, além da maior transparência e controle social. Nesse cenário, os governos devem se valer de servidores públicos capacitados com competências digitais necessárias para esse ambiente diverso e desafiador. Esse quadro se configura pela alta demanda por formação de qualidade de servidores, que serão responsáveis por coordenar e assegurar a implementação das estratégias de governos digitais (KREGEL e OGONEK, 2018; OCDE, 2018).

Coelho (2008) destaca diversas lacunas que tolhem a formação acadêmica dos estudantes de graduação em Administração Pública (AP) no Brasil, limites esses que perpassam pela atração dos alunos em ingressarem nos cursos até a futura inserção e retenção profissional. O desgaste da imagem do Estado é um dos fatores que desestimulam os alunos a cursarem AP. Associa-se o serviço público à ineficiência, incompetência política e incapacidade administrativa, o que resulta em ceticismo e estereótipos em relação ao Estado.

Outro problema destacado pelo autor é a carência de desenvolvimento de técnicas administrativas adequadas às especificidades da gestão pública. Isso se traduz, por um lado, em privilegiar conteúdos teóricos oriundos da administração de empresas em razão da pouca produção científica na área de AP. Por outro, a tensão da política versus a administração subsiste frente a rivalidade entre politicismo e o tecnicismo, ou entre a governança e o gerencialismo, concepção e execução (COELHO, 2008).

No contexto de governo eletrônico, que utiliza as TIC combinadas com mudanças organizacionais no setor público, são requeridos administradores públicos com conhecimentos e habilidades para operar na fronteira entre as políticas e as técnicas administrativas. Para tanto, são necessárias novas competências gerenciais e político-administrativas, que associem as habilidades gerenciais atreladas ao uso das Tecnologias de Informação e Comunicação na perspectiva do governo eletrônico e às condições legais para a operacionalização das políticas públicas (COELHO, 2008; KREGEL e OGONEK, 2018).

Também é apontado por Coelho (2008) que falhas na interface entre a teoria e a prática são reconhecidas pelo corpo discente e docente dos cursos de graduação em AP. Alguns dos fatores apontados pelo autor como motivos para essas falhas são o subaproveitamento da expertise de parte do corpo docente e a falta de estágios estruturados para a habilitação em AP; além do vínculo frágil das universidades com o setor público e a insuficiência de projetos de iniciação científica e extensão acadêmica; bem como gaps de competência de direção e domínio ferramental. Com a expansão das TIC nas atividades governamentais, a adoção de estratégias para inserir conteúdos que envolvam temáticas relacionadas a abordagens práticas em TI nos cursos de formação para os alunos do campo de públicas é um caminho para aprimorar os processos na administração pública. Os produtos e serviços digitais necessários para a eficácia e eficiência do governo eletrônico carecem de competências digitais que podem ser adquiridas no ensino superior, em cursos de formação, especialização e de capacitação.

Notadamente, a transformação digital do setor público enfrenta desafios não apenas relacionados à atração, ao desenvolvimento à e retenção de profissionais com o conjunto adequado de habilidades, mas também pela necessidade de desenvolver competências digitais e de conscientização entre os dirigentes, decisores e implementadores de política. Liderança e competências digitais entre funcionários públicos estão entre os fatores mais críticos para a evolução no sentido de uma política sustentável e consistente de governo digital (OCDE, 2018)

A transformação digital exige que os governos priorizem o desenvolvimento de novas competências e habilidades para abordar o novo ambiente de políticas públicas, em um cenário em que as competências digitais ainda são geralmente entendidas como uma capacidade técnica, e não como um ativo fundamental para a maioria dos perfis profissionais, sobretudo aqueles com níveis consideráveis de senioridade. Nesse sentido, também é necessário o desenvolvimento de uma cultura de concepção digital entre servidores públicos para fomentar o entendimento de que a transformação digital não é uma questão meramente 
técnica, mas uma realidade transversal que deve ser abordada com habilidades que vão muito além dos domínios técnicos (OCDE, 2018).

\section{Competências Digitais na Administração Pública: Análise Aplicada à Formação e à Atuação de Gestores Públicos}

Com base nas informações e nos dados coletados conforme descrito na metodologia, desenvolveu-se a análise aqui apresentada e organizada em duas seções. A primeira refere-se ao estudo das matrizes curriculares de cursos de formação do campo de públicas, bem como à percepção de alunos e de especialistas sobre conteúdos desenvolvidos nos cursos e sobre as competências digitais dos estudantes. A segunda perspectiva relaciona-se às competências digitais na atuação dos gestores públicos, seus principais desafios e tendências, estudo que foi arcabouçado pela análise qualitativa referente à participação de estudantes e especialistas na pesquisa, além de estudos anteriores que trazem evidências sobre a atuação de gestores públicos e o uso de tecnologias no setor público.

\subsection{Análise das competências digitais no âmbito da formação de gestores públicos}

De maneira a suscitar o desenvolvimento de competências digitais em estudantes de cursos do campo de públicas, devem ser levadas em consideração múltiplas variáveis, e uma de suma importância é a abordagem da temática da tecnologia, seja diretamente, em disciplinas de Informática, Sistemas de Informação, Governo Eletrônico, etc., seja indiretamente, em matérias de Estatística, Gestão de Processos, Métodos Quantitativos, etc., em que são ministrados conteúdos tecnológicos como Excel, Bizagi, linguagens de programação, ferramentas de georreferenciamento, dentre outras, ao decorrer das disciplinas, conforme detalhado na metodologia.

Tendo em vista essas questões, a análise dos projetos pedagógicos e das matrizes curriculares de cursos do campo de públicas das dez instituições pesquisadas no presente estudo foram realizadas em 11 cursos, uma vez que uma das instituições oferece o mesmo curso nas modalidades presencial e à distância, porém, com matrizes curriculares distintas. Desses onze cursos analisados, dois são à distância. Foi elaborado o cálculo, pois, da carga horária de disciplinas desses cursos que tratam da Tecnologia da Informação, direta e indiretamente, em relação à carga horária total do curso referente às disciplinas obrigatórias. As disciplinas optativas não foram analisadas, haja vista que algumas das instituições não possuem grades fixas com relação a matérias eletivas, tendo sido levadas em conta, pois, somente as disciplinas obrigatórias.

Os resultados encontrados evidenciam uma incidência baixa de disciplinas que tratam de tecnologias. A média de disciplinas que abordam TI diretamente foi de 3,8\% do total do curso, sendo que um dos onze cursos analisados sequer possui em sua matriz ao menos uma disciplina do tipo. A média de matérias que tratam indiretamente do tema, por sua vez, foi de $6,55 \%$, e a soma de disciplinas que versam direta e indiretamente sobre tecnologias foi superior a $15 \%$ em somente um dos cursos analisados. O Gráfico 1 apresenta a carga horária das disciplinas sobre tecnologias de informação em relação à carga horária total de cada curso. Os nomes das instituições foram omitidos de modo a preservá-las. 
Gráfico 1 - Percentual da carga horária de disciplinas que abordam a temática de tecnologias em relação à carga horária total dos cursos do campo de públicas das dez mais bem colocadas instituições segundo o Conceito Enade 2015 a partir dos projetos pedagógicos e matrizes curriculares vigentes em 2019.

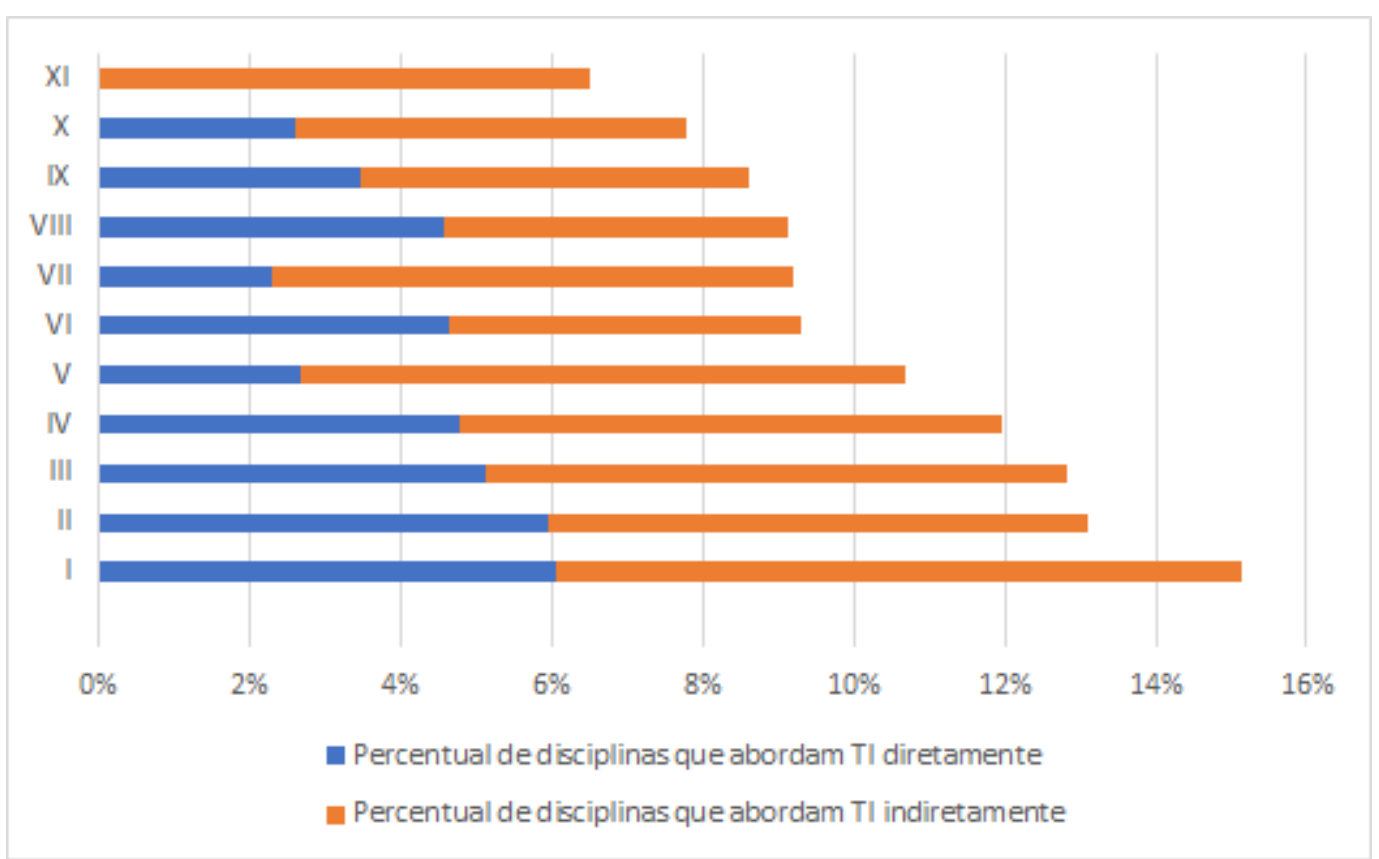

Fonte: Elaboração própria.

É interessante observar que nem dentre os cursos de graduação à distância analisados, que pressupõem por sua própria natureza um maior fomento ao desenvolvimento de competências digitais, os resultados encontrados não se destacaram em contraste com os cursos presenciais. Observa-se, pois, que a abordagem das tecnologias nos cursos do campo de públicas estudados ainda é pouco desenvolvida. Isso se configura como uma dificuldade, haja vista a crescente expansão das tecnologias no século XXI e a exigência de novas competências digitais para futuros gestores públicos.

Um dos entrevistados acredita que esse resultado pode estar associado a uma tradição de formação acadêmica no campo de públicas que secundariza a gestão, o que inclui a gestão informacional e de dados, e sobrevaloriza a dimensão da análise política. Esse viés atravanca a abordagem de aspectos gerenciais e instrumentais nos cursos, o que pode explicar a baixa incidência de disciplinas sobre tecnologias, em especial aquelas que trazem não apenas certas noções de informática, mas que tratam de temas complexos das tecnologias aplicadas à gestão pública e que levantam discussões sobre aspectos sociotécnicos e sistemas abertos, como a temática da governança digital.

Em outra das entrevistas realizadas, foram relatados indícios de que há uma intenção por parte de algumas das instituições analisadas de alterar esse quadro, a partir de uma reformulação das grades curriculares, de modo a promover uma adequação ao contexto da era digital e de seus impactos no setor público. Há o intuito de se inserir mais disciplinas obrigatórias na área de TI, com conteúdos sobre Big Data, Data Science, ferramentas de georreferenciamento, dentre outros. Observa-se, pois, que há uma incipiente tentativa de mudança, o que é positivo, haja vista que os resultados observados pautados nas matrizes curriculares vigentes sinalizam pouca ênfase em disciplinas que tratam de tecnologias.

As respostas obtidas no questionário aplicado entre estudantes do campo de públicas das dez melhores colocadas instituições segundo o Conceito Enade 2015 corroboraram com a análise realizada a partir dos projetos pedagógicos dos cursos. Segundo os alunos, a oferta dessas disciplinas é baixa ou até mesmo 
inexistente. Além disso, a maior parte deles afirmou que nunca participou ou teve conhecimento acerca de eventos ou palestras promovidos pela instituição de ensino sobre a temática da tecnologia aplicada à gestão pública.

O estudo do Quadro de Competências Digitais para Cidadãos orientou o presente trabalho no sentido de verificar o nível de proficiência no que tange às competências digitais em que se encontram os estudantes dos cursos analisados. Como abordado no referencial teórico, existem cinco áreas de competência, que se subdividem em níveis de proficiência a partir de resultados de aprendizagem, em uma escala de 1 a 8 . Esperava-se que a maior parte dos estudantes se encontrassem em níveis de proficiência intermediários ou avançados dessas competências, ou seja, entre os níveis 3 e 6 . A partir de uma breve explicação para os respondentes acerca do significado de cada dimensão do Quadro, eles identificaram suas competências digitais de acordo com o nível em que avaliavam se encontrar.

Com relação à primeira área de competência, referente à literacia de informação e de dados, os respondentes se identificaram, em grande maioria (quase $70 \%$ ), no nível altamente especializado, que corresponde aos valores 7 e 8 na escala. De acordo com o Quadro, um indivíduo que possui esses níveis de proficiência para a referida competência é capaz de criar soluções para problemas complexos relacionados à navegação, filtragem de dados e informações, avaliação de fontes de dados, armazenamento de conteúdo, dentre outros, além de conseguirem criar novas ideias e soluções para essa área. Apenas $6 \%$ dos estudantes se consideram em um nível intermediário, e nenhum em um nível básico.

Esse resultado foi semelhante no que diz respeito à segunda seara de competência descrita no Quadro, que está relacionado à comunicação e colaboração. Quase $60 \%$ dos respondentes classificaram sua proficiência nessa competência no nível 8, o mais avançado possível. Isso significa que eles seriam capazes, por exemplo, de criar soluções para resolver problemas complexos e com muitos fatores que interagem entre si no que diz respeito à interação por meio de tecnologias digitais e meios de comunicação, compartilhamento de informações, participação social a partir da utilização de serviços digitais públicos e privados, processos colaborativos, e, também, de propor ideias e soluções inovadoras e criativas para a área.

Já no que concerne à terceira esfera de competência, que abarca a criação de conteúdo digital, a maior parte (quase $60 \%$ ) dos estudantes considera que possui um nível 5 de proficiência, o que corresponde a um resultado avançado, mas não altamente especializado. Nesse patamar, os indivíduos têm capacidade de orientar pessoas quanto à produção de conteúdos digitais, criar e editar conteúdos em diferentes formatos, modificar e aperfeiçoar itens diversos de conteúdo e informação, compreender e aplicar diferentes regras quanto a direitos autorais, dentre outros aspectos.

Com relação à quarta área de competência, que corresponde à segurança no meio digital, os estudantes se identificaram, em maioria (pouco mais de 60\%), nos níveis 5 e 6, ou seja, avançados. Eles seriam capazes de, por exemplo, aplicar as medidas mais apropriadas para evitar riscos na rede, proteger informações e conteúdos próprios e de outros, avaliar declarações de política de privacidade e evitar riscos à saúde no meio digital. Essa foi a única área em que uma parte dos respondentes (cerca de 6\%) se classificaram no nível 1, o mais básico possível, e 25\% deles consideram que se encontram nos níveis 3 e 4, ou seja, intermediários. Isso evidencia que parte considerável dos estudantes não se considera confiante quanto a esse tema em comparação com as demais esferas de competência.

Por fim, quanto à quinta seara de competência, mais de $60 \%$ dos alunos consideraram que se encontram nos níveis 5 e 6 de proficiência (avançados). De acordo com o Quadro, indivíduos nesses níveis conseguem avaliar problemas técnicos e resolvê-los de diferentes formas, aplicar ferramentas digitais diversas para sanar necessidades tecnológicas, adaptar as tecnologias para criar conhecimento e inovar processos e produtos. Cerca de $30 \%$ dos estudantes julgaram, ainda, estar nos níveis 7 e 8 , ou seja, altamente especializados. 
Uma análise geral das respostas dos graduandos acerca de suas competências digitais possibilita dizer que eles possuem níveis avançados, ou até mesmo extremamente especializados, de proficiência em todas as áreas. Contudo, é possível que as considerações feitas pelos estudantes no campo teórico das competências digitais não correspondam efetivamente à realidade na esfera prática, no que diz respeito, por exemplo, ao conhecimento e manuseio de determinados sistemas e ferramentas, à realização de atividades específicas que demandam conhecimentos tecnológicos, à construção de planilhas utilizando recursos complexos, dentre outros conteúdos que permeiam a rotina de trabalho de gestores públicos.

Levando em consideração esses fatores, os alunos foram questionados, ademais, acerca de suas experiências pessoais ao longo do curso, levando em consideração conteúdos que foram demandados em estágios e atividades de extensão e imersão, além de seus conhecimentos acerca de ferramentas específicas e suas percepções sobre o uso da tecnologia por gestores públicos.

Alguns alunos relataram ter recebido alguns treinamentos e cursos de capacitação na área de TI em estágios e em atividades de extensão - empresas juniores, por exemplo. Contudo, esses treinamentos se deram de maneira complementar ao curso e abordaram conteúdos mais simples, como Excel básico. A despeito da baixa incidência de disciplinas que abarcam o desenvolvimento de competências digitais nos cursos e da incipiente oferta de cursos complementares de capacitação, todavia, os estudantes afirmaram que foram demandados quanto à realização de atividades que requerem conhecimentos tecnológicos específicos. Foram citados: uso do Excel e de outros programas que integram o pacote Office, programação, conhecimento de softwares de georreferenciamento como o QGIS, utilização de programas de webdesign como o Corel Draw, operação de ambientes estatísticos como o $\mathrm{R}$ e manuseio de sistemas utilizados internamente em organizações governamentais.

Os respondentes identificaram, ademais, sua percepção de conhecimento acerca de ferramentas específicas, muitas delas inclusive citadas por eles no item anterior. O Gráfico 2 destaca os resultados consolidados desse levantamento no que se refere ao domínio sobre o uso da ferramenta Excel.

Gráfico 2 - Percentual de estudantes brasileiros do campo de públicas em relação à percepção de seu conhecimento sobre o programa Excel em 2019.

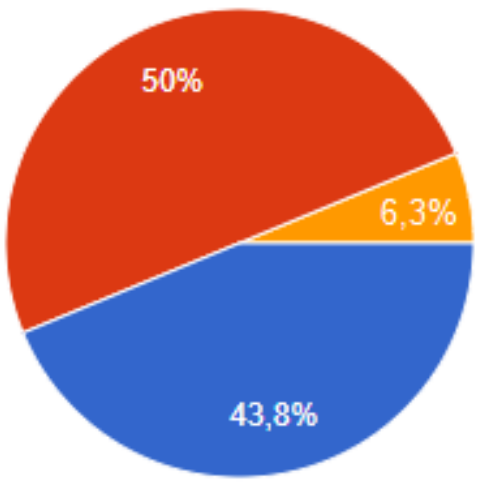

Conhece e sabe utilizar sem dificuldades

Conhece e sabe utilizar com certas dificuldades

Conhece e sabe utilizar com muitas dificuldades

Conhece, mas não sabe como utilizar

Não conhece

Fonte: Elaboração própria.

Os resultados demonstrados no Gráfico 2 evidenciaram que todos os respondentes consideram conhecer a referida ferramenta e sabem utilizá-la. No entanto, a maioria dos estudantes respondentes afirmam ter certas dificuldades no uso do Excel. Outro pequeno grupo entende que possuem grandes dificuldades. O Gráfico 
2 informa também que boa parte dos respondentes considera que sabe utilizar a ferramenta sem dificuldades.

O resultado foi semelhante no que diz respeito ao conhecimento sobre ferramentas de apresentações, como o Power Point e o Canva. Nesse caso, $50 \%$ dos respondentes afirmaram que conhecem algumas dessas ferramentas e sabem utilizá-las sem dificuldades, enquanto $37,5 \%$ conhecem várias e sabem utilizá-las sem dificuldades e 12,5\% conhecem algumas e sabem utilizá-las com dificuldades.

Dessa maneira, observa-se que os estudantes possuem, em geral, uma boa familiaridade com ferramentas que são comumente utilizadas no cotidiano de servidores públicos. Contudo, no que tange a conhecimentos um pouco mais aprofundados e que poderiam trazer soluções inovadoras para o setor público por meio do ambiente tecnológico, nota-se ainda uma incipiência por parte dos alunos. Isso pôde ser observado quando eles foram demandados acerca do conhecimento de softwares e ambientes estatísticos como o R e o SPSS. Os resultados apontam que a maior parte deles não conhece nenhum, e grande parte conhece alguns, mas não sabe como utilizá-los. Apenas $25 \%$ dos respondentes conhecem as ferramentas, sendo que apenas $6,3 \%$ conhecem várias e sabem utilizá-las sem dificuldades.

Gráfico 3 - Percentual de estudantes brasileiros do campo de públicas em relação à percepção de seu conhecimento sobre de softwares e ambientes estatísticos em 2019.

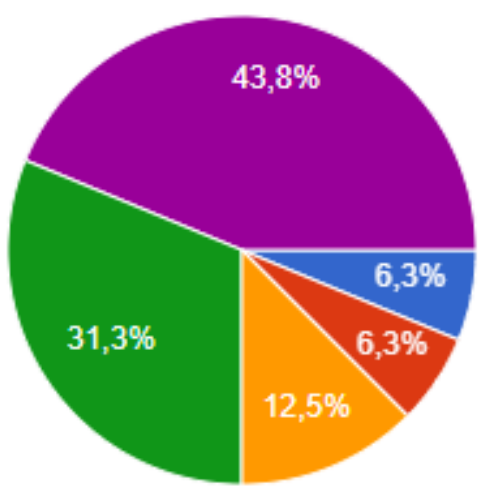

Conhece vários e sabe utilizá-los

Conhece alguns e sabe utilizá-los

Conhece alguns e sabe utilizá-los com dificuldades

Conhece alguns, mas não sabe como utilizá-los

Não conhece

Fonte: Elaboração própria.

Respostas semelhantes foram dadas quando os estudantes foram perguntados acerca do conhecimento de ferramentas de webdesign, como o lllustrator. Nesse caso, 37,5\% dos respondentes afirmaram que não conhecem ambientes do tipo e 37,5\% disseram que conhecem algumas, mas não sabem como utilizá-las. Apenas $25 \%$ dos estudantes alegaram conhecer algumas dessas ferramentas, sendo que $18,8 \%$ disseram ter dificuldades ao utilizá-las.

\subsection{Análise das competências digitais no âmbito da atuação de gestores públicos}

Os resultados da autoavaliação de estudantes do campo de públicas quanto às suas competências digitais, apresentados na última seção, podem sugerir que eles, enquanto futuros gestores públicos, possuem competências para lidar com ferramentas digitais de uso comum no dia a dia do serviço público, mas que não necessariamente trazem soluções criativas e novos impactos para a Administração Pública. Quintino 
(2019), ao analisar o contexto do controle da aquisição de medicamentos no âmbito do estado de Minas Gerais, deparou-se com uma realidade que corrobora com essa perspectiva. A autora verificou que, no órgão responsável por essas compras, há um costume de se utilizar o SEI (Sistema Eletrônico de Informações) para a quase totalidade de atividades ali exercidas, inclusive para fins de controle. Tal comportamento evidenciou-se inadequado, haja vista que o sistema, que tem por objetivo a tramitação e o compartilhamento de documentos institucionais, não deveria ser associado à estratégia de controle, que é uma das funções básicas da Administração e que pressupõe uma comparação entre o que foi planejado e o que foi executado, e não um mero registro documental.

A autora destaca que, no setor em questão, um servidor entrevistado é responsável por fazer todo o controle efetivo (com relatórios acerca do planejamento e da execução das compras) sozinho, a partir de uma planilha no Excel, que é atualizada de maneira contínua. Esse, contudo, não é um comportamento institucionalizado, mas uma atitude individual, o que evidencia que o órgão não utiliza as ferramentas tecnológicas em seu favor a partir de uma lógica coletiva. O modus operandi organizacional se caracteriza por recorrer sempre às tecnologias comumente usadas, mas não há iniciativa em propor soluções distintas por meio de outras ferramentas digitais que poderiam dinamizar os processos do órgão, o que pode ser fruto de uma carência no desenvolvimento de competências digitais.

Um dos professores entrevistados acredita que o setor público ainda não tenha absorvido o impacto da expansão das tecnologias de maneira desejável, o que é claramente observado no cenário do controle da compra de medicamentos em Minas Gerais apresentado por Quintino (2019). Dessa forma, embora o professor acredite que os novos ingressantes na Administração Pública tenham bons níveis de competência no que se refere à literacia digital, é interessante que os governos convirjam na direção de um processo de especialização dos gestores públicos quanto às demais áreas de competências digitais, de modo que as organizações se adequem à era digital de maneira sistêmica. Isso evitaria que o uso de ferramentas tecnológicas que inovem processos em órgãos públicos fosse concentrado em uma só pessoa, como acontece no contexto do setor de aquisição de medicamentos anteriormente descrito.

Os estudantes do campo de públicas que responderam ao questionário também relataram ter observado, em atividades de extensão, imersão ou estágio, gestores públicos com dificuldades para lidar com ambientes tecnológicos. Um dos respondentes afirmou que os servidores do setor em que fazia estágio tinham problemas em utilizar os sistemas informatizados mais novos, e insistiam em usar os antigos, uma vez que já estavam acostumados em trabalhar com eles. Um outro estudante relatou que observou gestores que sequer tinham conhecimento sobre como preencher os sistemas internos, e resolviam boa parte dos problemas entrando em contato por telefone ou e-mail com outros servidores. Um terceiro graduando comentou que notou essas dificuldades em dois estágios distintos, e pontuou a primordialidade da capacitação tecnológica de gestores públicos desde o pacote Office até linguagens de programação.

Em consonância com essa perspectiva, ao argumentar sobre a importância de se inserir mais conteúdos sobre tecnologias na formação de gestores públicos, pois, um dos respondentes do questionário trouxe a seguinte contribuição:

É muito importante, visto que o gestor público passa pelo menos $80 \%$ do tempo de seu serviço em frente a um computador. Esse indivíduo tem a necessidade de conhecer os instrumentos necessários para trabalhar os dados que produz. Em meu estágio curricular percebi que a função "planejamento" fica muito perdida em função disso; ou seja, a falta de conhecimento técnico, principalmente dos servidores mais antigos, faz com que o tempo no serviço que deveria ser destinado ao estudo mais aprofundado das perspectivas organizacionais se torne ocioso. Os indivíduos acabam ficando limitados apenas às atividades rotineiras porque não possuem o conhecimento técnico para analisar, por meio dos programas, os dados que produzem. Outra coisa interessante de ser percebida é a dificuldade da maioria dos servidores de se adaptarem às inovações dos sistemas, e os treinamentos não são suficientes para o completo aprendizado. Essa dificuldade pode gerar 
atrasos no serviço, representando uma inversão daquilo que era pretendido com a implantação de um novo sistema, que é justamente a maior agilização do trabalho (RESPONDENTE).

Dessa maneira, o estudante destaca a relevância de uma formação que prepare os gestores públicos para o contexto da era digital, de modo que eles sejam capazes de utilizar a tecnologia com a finalidade de dinamizar e inovar os processos no setor público, para além dos sistemas rotineiros tradicionais. Outro respondente foi ao encontro desse ponto de vista, dizendo que gestores públicos em formação devem receber capacitação quanto ao uso de tecnologias, haja vista que a tendência contemporânea é o uso crescente de aparelhos eletrônicos, softwares e sistemas, o que também se aplica ao serviço público. Investir no desenvolvimento de competências digitais traria, pois, segurança e economia para a Administração Pública.

Uma professora entrevistada acredita que a expansão das tecnologias no setor público pode acarretar uma melhoria na qualidade dos processos da Administração Pública, para além da questão da redução de custos. Ela considera que práticas democráticas, como fóruns, podem ser melhoradas, que os cidadãos podem ser atendidos com maior igualdade, e que novas formas de governança podem ser exercidas. A professora entende, ainda, que as tecnologias possibilitam que políticas públicas sejam desenhadas de maneira mais eficiente, a partir de dados e evidências. Dois respondentes do questionário também mencionaram esse aspecto. Segundo um deles, gestores públicos devem ter competências digitais para planejar e desenvolver uma política a partir do conhecimento de bases de dados, enquanto o outro destacou que saber utilizar ferramentas estatísticas complexas é fundamental para a construção de indicadores capazes de avaliar o impacto de políticas públicas de maneira efetiva.

\section{Conclusões}

A partir das análises realizadas, conclui-se que, no contexto da formação e da atuação de gestores públicos, as competências digitais se configuram de forma incipiente. No âmbito das matrizes curriculares e dos projetos pedagógicos dos cursos estudados, percebem-se evidências de uma pouca ênfase dada a conteúdos voltados para o desenvolvimento de competências digitais. Além disso, embora a percepção dos estudantes denote destreza no uso de recursos tecnológicos, verifica-se que seu conhecimento se restringe a ferramentas digitais pouco sofisticadas, conhecimento esse que foi adquirido com certa naturalidade pelas gerações nascidas no final do século XX e início do século XXI. Para esses indivíduos, a familiaridade com tecnologias possibilita que eles tenham um maior domínio com relação à área de competência da literacia digital. Não obstante, outras áreas de competência ainda são pouco desenvolvidas. Essa constatação é reforçada quando os respondentes manifestam desconhecer ferramentas digitais mais complexas, capazes de subsidiar a resolução de problemas e o processo decisório. Os especialistas entrevistados corroboram com esse entendimento ao sugerir preocupações com o direcionamento dos conteúdos dos cursos do campo de públicas.

Sob um outro olhar, no que se refere às competências digitais no âmbito da atuação dos gestores públicos, a pesquisa retrata um cenário ainda desafiador e que deve merecer atenção, uma vez que um maior desenvolvimento de competências digitais poderia impulsionar novas soluções e ampliar as capacidades do gestor público no exercício de suas funções. Isso favorece a construção de uma Administração Pública mais eficiente, em prol dos interesses da sociedade, com foco na melhoria da prestação de serviços e na ampliação de canais de diálogo e de interlocução inter e intrainstitucionais. Além disso, um ambiente em que os gestores públicos utilizam de forma plena suas competências digitais contribui para o aprimoramento das relações entre governos e cidadãos e para a democratização do espaço público. 
Os estudos aqui desenvolvidos trazem para a pauta de discussão uma temática fundamental para o século $\mathrm{XXI}$, de forma a dar um sinal de alerta para que os cursos do campo de públicas estejam atentos para a necessidade de uma mudança da metodologia de formação. Os gestores públicos do futuro devem desenvolver competências que os capacitem para os desafios do futuro, sendo que, dentre essas, as competências digitais assumem um papel de grande relevância. Uma sociedade conectada precisa de um governo com gestores públicos preparados para a era digital.

\section{Referências}

ALA-MUTKA, Kirsti. Mapping Digital Competence: Towards a Conceptual Understanding. Luxemburgo, 2011.

BRASIL. Instituto Nacional de Estudos e Pesquisas Educacionais Anísio Teixeira. Conceito Enade. Brasília, 2019. Disponível em: < http://portal.inep.gov.br/conceito-enade>. Acesso em 01 jun. 2019.

CARRETERO, S.; VUORIKARI, R; PUNIE, Y. The Digital Competence Framework for Citizens. União Europeia, 2017. Disponível em:

$<$ https://publications.jrc.ec.europa.eu/repository/bitstream/JRC106281/web-digcomp2.1pdf (online).pdf $>$.

COELHO, F. S. A problemática atual do ensino de graduação em administração pública no Brasil.

Cadernos EBAPE.BR, Rio de Janeiro, p. 1-21, 2008. Disponível em:

$<$ http://www.scielo.br/pdf/cebape/v6nspe/v6nspea08.pdf>.

COMISSÃO EUROPEIA. Learning Opportunities and Qualifications in Europe. Bélgica, 2019.

Disponível em : <https://ec.europa.eu/ploteus/search/site?f[0]=im field entity type\%3A97\#>. Acesso em 20 jun. 2019.

GIL, A. C. Métodos e técnicas de pesquisa social. 6. ed. São Paulo: Editora Atlas SA, 2008. Disponível em: <https://ayanrafael.files.wordpress.com/2011/08/gil-a-c-mc3a9todos-e-tc3a9cnicas-de-pesquisasocial.pdf $>$.

KREGEL, I.; OGONEK, N. Digital Lean Competencies: Requirements for Public Administration. Seventh International Conference on Lean Six Sigma: Dubai, 2018.

LUCAS, M.; MOREIRA, A. DigComp 2.1: Quadro Europeu de Competência Digital para Cidadãos: com oito níveis de proficiência e exemplos de uso. Aveiro: UA, 2017. Disponível em:

$<$ https://www.erte.dge.mec.pt/sites/default/files/Recursos/Estudos/digcomp2.1 $0 . p d f>$.

MARTIN, Allan. DigEuLit-a European framework for digital literacy: a progress report. Journal of eLiteracy, v. 2, n. 2, p. 130-136, 2005. Disponível em:

$<$ http://citeseerx.ist.psu.edu/viewdoc/download?doi=10.1.1.469.1923\&rep=rep1\&type=pdf > .

MOELLER, S. et. al. Towards Media and Information Literacy Indicators. Paris: Unesco, 2011.

Disponível em: <https://www.ifla.org/files/assets/information-literacy/publications/towards-media-andInformation-literacy-indicators.pdf>.

OCDE - Organização para a Cooperação e Desenvolvimento Econômico. Organização para a Cooperação e Desenvolvimento Econômico. Revisão do Governo Digital do Brasil Rumo à Transformação Digital do Setor Público. Brasil, 2018. Disponível em:

$<$ http://editor.planejamento.gov.br/seminariodigital/seminario/digital-gov-review-brazil-portugues.pdf $>$.

QUINTINO, M. E. A. Gestão da informação e controle da qualidade no âmbito das compras públicas: uma análise na aquisição de medicamentos em Minas Gerais. Trabalho de conclusão de curso Fundação João Pinheiro, Belo Horizonte, 2019. Disponível em:

$<$ http://monografias.fjp.mg.gov.br/bitstream/123456789/2601/1/Milla\%20Eugenia.pdf>. 
RADA, V.; VIDAL, C.; CERVERA, M. Los componentes de la competencia digital. In: CONGRESO INTERNACIONAL "COMUNICACIÓN Y EDUCACIÓN: Estrategias de alfabetización mediática", 1., 2011, Barcelona. Disponível em: <https://www.uda.ad/wpcontent/uploads/2010/01/cice larraz espuny gisbert 2011 05.pdf>.

SANTOS, R; AZEVEDO, J; PEDRO, L. Literacia(s) digital(ais): definições, perspetivas e desafios. Coimbra, 2015.

SEBASTIÃO, S. P. A Literacia Digital e a Participação Cívica. Educação, Sociedade \& Culturas, oㅡ 42, p. 111-132. Lisboa, 2014. Disponível em: $<$ https://www.fpce.up.pt/ciie/sites/default/files/ESC42 09SoniaSebastiao.pdf>.

SILVA, K. K. A; BEHAR, P. A. Competências digitais na educação: uma discussão acerca do conceito. Educação em Revista, Belo Horizonte, v. 35, 2019. Disponível em:

<http://www.scielo.br/scielo.php?pid=S0102-46982019000100419\&script=sci arttext $>$.

VAN DEURSEN, A. J. A. M. Internet skills: vital assets in an information society. Enschede: University of Twente, 2010. 